\title{
REMINERALIZATION POTENTIAL OF CHICKEN EGGSHELL POWDER IN THE TREATMENT OF ARTIFICIALLY INDUCED ENAMEL CARIOUS LESION IN PERMANENT TEETH
}

\author{
Eman Mohamed Sobhy Elbahrawy* and Ahmed Ibrahime El -Dosoky **
}

\begin{abstract}
Objectives: This study aimed to assess and compare the enamel remineralization potential of chicken eggshell powder (CESP) solution or slurry on initial enamel caries in permanent teeth.

Materials and methods: 20 caries-free human premolars were used in this study. The mineral content and surface microhardness of all specimens were initially assessed using EDX and Vickers microhardness tester respectively (positive control group). The specimens were artificially demineralized for 96 hours and then reassessed directly after demineralization (negative control group). All demineralized specimens were randomly divided into two equal groups according to the remineralization regimen used : group(I) 10 specimens were immersed in CESP solution for 12 mins, while group (II) : 10 specimens were finger rubbed with CESP slurry for 2 mins. The remineralizing agent was applied twice daily for 7 successive days. After that, the specimens were reassessed for mineral content $\left(\mathrm{Ca}\right.$ and $\mathrm{PO}_{4}$ weight $\left.\%\right)$ and surface microhardness. Finally, the $\mathrm{pH}$-cycling models were used for each group followed by reassessment. The data was statistically analyzed using repeated measures analysis of variance (ANOVA). All analysis was performed with a significance level set at $5 \%(\mathrm{P} \leq 0.05)$..
\end{abstract}

Results: There was significant decrease in both $\mathrm{Ca}$ and $\mathrm{PO}_{4}$ weight $\%$ after demineralization in all specimens and then it was significantly increased after treatment with remineralizing agents as detected by EDX $(\mathrm{p}<0.001)$. Vickers microhardness results confirmed elemental analysis results. However, there was no statistical significant difference between the two remineralized groups. In addition, there was no statistically significantly difference in the mean Ca/P wt $\%$ between (after $\mathrm{pH}$ cycling models ) and that of sound enamel in both groups. Also, there was no statistically significant difference in the mean $\mathrm{Ca} / \mathrm{P}$ wt\% between the two remineralization regimen (Gp I and Gp II) when comparing each step separately. Comparing the microhardness of enamel specimens between the four steps of the study (Sound enamel, demineralized enamel, treatment with CESP and $\mathrm{pH}$ cycling after treatment) revealing a statistically significant difference between 4 steps in both group I\& II except for the comparison between treatment with CESP and $\mathrm{pH}$ cycling after treatment

*Lecturer of Dental Biomaterials, Department of Dental Biomaterials, Faculty of Dentistry, Tanta University, Tanta, Egypt

**Lecturer of Oral health \& Preventive Dentistry, Faculty of Dentistry, Tanta university, Egypt 
Conclusions: CESP has a promising future in treating initial enamel surfaces lesion due to its natural source and easy bioavailability. Remineralization using CESP solution has a similar efficacy to that of topical application of CESP slurry using finger rubbing.

KEY WORDS: Enamel Demineralization; Chicken eggshell powder; Remineralization; Scanning Electron Microscope-Energy Dispersive X-ray; Surface Microhardness.

\section{INTRODUCTION}

Dental caries is a highly predominant multifactorial disease and has been a major public health problem for many centuries. The outcome of dental caries is regulated by the dynamic balance between pathological factors that resulted in demineralization and protective factors that resulted in remineralization ${ }^{[1,2]}$.

In a neutral environment, the hydroxyapatite of the enamel is in equilibrium with saliva which is saturated with calcium and phosphate ions ${ }^{[3]}$. At or below $\mathrm{pH} 5.5, \mathrm{H}^{+}$ions produced by the bacterial metabolites that react preferentially with the phosphate group of the enamel crystals, converting $\left(\mathrm{PO}_{4}\right)^{-2}$ ion to $\left(\mathrm{HPO}_{4}\right)^{-2}$ ion which, once formed, can no more form the crystal lattice; at the same time $\mathrm{H}^{+}$ ions are buffered. This leads to enamel dissolution, termed as demineralization, which signals early enamel caries ${ }^{[4]}$.

However, the demineralization can be reversed if the $\mathrm{pH}$ is neutralized and there are adequate calcium and phosphate ions available in the surrounding environment. This enables the rebuilding of partially dissolved hydroxyapatite crystals in the process of remineralization. To restore the natural equilibrium, either remineralization must be accelerated or demineralization must be retarded ${ }^{[5]}$.

Several remineralizing agents have been tested in the treatment of the early enamel carious lesion both in-vivo and in-vitro like fluoride, hydroxyapatite, Casein Phosphopeptide-Amorphous Calcium Phosphate (CPP-ACP), antibacterial bonding agents, some nutritional and herbal medicaments, laser, Xylitol and Ozone ${ }^{[6-8]}$.
Normally, remineralization by fluoride is a selflimiting surface phenomenon that inhibits diffusion of calcium and phosphate ions required to rebuild the carious lesion in depth ${ }^{[9]}$. This is due to rapid deposition of fluoroapatite which is more resistant to further demineralization ${ }^{[10]}$.

In 1992, Eggshell (ES) powder was reported as a medicinal and pharmaceutical agent used as a bone substitute for treatment of maxillofacial defects and alternative to bone grafts for regeneration of bone defects ${ }^{[11,12]}$. It was registered as a rich source of Calcium, containing 94\% Calcium Carbonate, 1\% Calcium Phosphate, 1\% Magnesium Carbonate, and $4 \%$ organic matter ${ }^{[13]}$. Also, it contains other elements such as Fluoride and Strontium. Despite their low concentration they have a positive effect on bone and dental metabolism ${ }^{[14,15]}$.

Recently, it was reported that Chicken egg shell powder (CESP) can be used in-vitro to increase the bone mineral density and it stimulates chondrocyte differentiation and cartilage growth ${ }^{[16]}$. However, scare studies have been analyzed the effect of CESP on remineralization of incipient enamel carious lesion ${ }^{[12,17]}$.

Chicken egg shell powder can be produced by the process of calcination; which is the heating of a solid below the melting point to create a state of thermal decomposition or phase transition other than melting. The conventional calcination temperature for calcium is $900^{\circ} \mathrm{C}$, at which the calcium carbonate decomposes into calcium oxide and carbon dioxide ${ }^{[18]}$.

Recently, the increasing emphasis on preventive and minimal intervention dentistry coupled with the established higher prevalence of non-cavitated 
caries compared to cavitated tooth surfaces is encouraging nonsurgical management of early carious lesions. Thus, there is need for effective treatment strategies to facilitate non-operative care of initial caries lesions (remineralization) ${ }^{[19]}$.

Thus the purpose of the present study was to assess and compare the enamel remineralization potential of CESP solution or slurry on early initiated demineralized enamel in human permanent teeth using Energy Dispersive X-ray Spectroscopy (EDX) and surface microhardness analysis. The null hypothesis was that CESP solution has the same remineralization effect as CESP slurry

\section{MATERIALS AND METHODS}

\section{Teeth collection and sample preparation}

Twenty sound, non-carious human first premolar freshly extracted for orthodontic purposes; were collected from the clinic of maxillofacial surgery, Faculty of Dentistry, Tanta University. The purpose of the present study was explained to the patient and informed consents were obtained to use their extracted teeth on the research according to the guidelines on human research published by the Research Ethics Committee at Faculty of Dentistry, Tanta University.

All calculus and soft deposits were removed from the teeth with hand scaler (Scaler 10A, NOVA instruments Ltd, BerkShire, UK). The teeth were cleaned using distilled water. Then, the teeth were carefully examined using magnifying glass and any tooth with visible cracks, hypoplasia, white spot lesion, or caries on any surface were excluded from the study ${ }^{[20]}$.

The teeth were stored in laboratory prepared artificial saliva \{prepared by mixing $500 \mathrm{ml}$ distilled water with $1.2 \mathrm{~g}$ Potassium Chloride, $0.843 \mathrm{~g}$ Sodium Chloride, $0.051 \mathrm{~g}$ Magnesium Chloride, $20 \mathrm{ml}$ stock solution of Tri-Calcium Phosphate (TCP) 1\% (10.5 g TCP and $200 \mathrm{ml}$ of $1.0 \mathrm{M}$ hydrochloric acid) and Carboxy-methylcellulose. Sodium Hydroxide $(0.05 \mathrm{M})$ was added to the mixture to have a $\mathrm{pH}$ of $6.8\}^{[21]}$. The teeth were stored in an incubator at $37^{\circ}$ $\mathrm{C}$ throughout all the steps of the study.

The teeth were decoronated at CEJ using slow speed diamond saw (Hard tissue microtome, Bronwill, E. McGranthinc, MA, USA). The coronal portion of each decoronated tooth then imbedded in self cured acrylic resin blocks (Acrostone, AngloEgyptian Company, Cairo, Egypt) with labial surfaces facing upward. The labial enamel surfaces of the specimens were ground using silicon carbide paper (grades 600-1200) under water irrigation to produce more consistent reproducible flat enamel surface $^{[12]}$.

\section{Quantitative elemental analysis (weight \%) by EDX}

Both Calcium (Ca) and Phosphorus (P) content of all specimens (positive control group / $n=20$ specimens) were analyzed quantatively using Energy Dispersive X-ray Spectrometry (EDX) (Ametek, Materials Analysis Division, Netherlands), computer controlled software Genesis using an accelerating voltage of $15 \mathrm{kV}$, Electron beams maintained at $2 \times 10^{-10}$ amp were used and X-ray intensities in counts per second were recorded. Elemental level including Calcium $(\mathrm{Ca})$ and Phosphorus $(\mathrm{P})$ were evaluated in weight percentage.

\section{Baseline Microhardness testing}

The baseline surface microhardness of all positive control specimens was analyzed using Digital Vickers Microhardness testing machine (ZwicRoell, west Midlands, England) with a Vickers' diamond indenter and 20X objective length. A load of 25g applied to the surface of the specimens for 5 seconds. Three indentations, which were equally placed over a circle and not closer than $0.5 \mathrm{~mm}$. to the adjacent indentations, were made on the surface of each specimen. The diagonals length of the indenter were measured by built-in scaled micrometer and values were changed over into Vickers' hardness numbers 
(VHN).The average values considered as the microhardness value of the corresponding specimen. VHN was calculated by the following equation:

\section{VHN: HV=1.854 P/d ${ }^{2}[9]$}

Where, $\mathbf{H V}$ was Vickers hardness in $\mathrm{Kg} / \mathrm{mm}^{2}$, $\mathbf{P}$ was the load applied in $\mathrm{Kg}$ and $\mathbf{d}$ was the average length of the diagonals in $\mathrm{mm}$ and $\mathbf{1 . 8 5 4}$ was a constant number.

\section{Demineralization Protocol}

The early artificial demineralization of enamel subsurface was achieved by immersing the specimens individually into glass container containing $20 \mathrm{ml}$ of laboratory prepared demineralizing solution (2.2 mMol Calcium Chloride, $2.2 \mathrm{mMol}$ Sodium Phosphate, $0.05 \mathrm{M}$ acetic acid and $1 \mathrm{Mol} \mathrm{Po-}$ tassium Hydroxide) in separate test tubes at $37^{\circ} \mathrm{C}$ for 96 hours. The $\mathrm{pH}$ of the solution was checked using digital $\mathrm{pH}$ meter (Deulxe deep vision, model no: 101, California, USA). and adjusted with $1 \mathrm{Mol}$ Potassium Hydroxide to a $\mathrm{pH}$ of $4.2^{\text {[22] }}$. The solution was changed daily to avoid supersaturation ${ }^{[23]}$. Elemental analysis (EDX) and surface Microhardness were evaluated for the demineralized specimens (negative control group/ $\mathrm{n}=20$ specimens)

\section{Grouping of the specimens}

Specimens were randomly divided into two equal groups ( $\mathrm{n}=10$ specimens /group) according to the remineralization regimen used, as follow:

Group I : Remineralization by immersion in CESP solution.

Group II: Remineralization by Finger rubbing with CESP slurry.

\section{Production and characterization of Chicken Eggshell Powder (CESP)}

The Chicken Eggshell Powder (CESP) was obtained by the process of calcination following the protocol given by World Property intellectual organization ${ }^{[24]}$. Thirty chicken eggs obtained from a local hatchery (Tanta). The contents were removed and the eggshells were cleaned in distilled water. The egg shells then kept in a hot water bath at $100^{\circ} \mathrm{C}$ for 10 minutes to facilitate removing the membrane. Then, the egg shells were crushed using a sterile mortar and pestle. The crushed particles then heated at $900^{\circ} \mathrm{C}$ in a muffle furnace (Lava Furnance 200, 3M, USA) for 1 hour and powdered to small particles ${ }^{[16,17]}$.

The characterization of the crystalline phases present in the raw and calcined CESP was performed by using an X-Ray Diffractometer (XRD) (40 kV and $40 \mathrm{~mA}$ ) (Bruker AXS-D8 X-ray diffractometer, ADVANCE, Germany) with $\mathrm{Cu} \mathrm{K} \alpha$ radiation $(\lambda=$ $0.154 \mathrm{~nm}$ ). The XRD patterns were recorded in the $2 \theta$ range $5^{\circ}-80^{\circ}$ with a step size of $0.01^{\circ}$. Then the morphology and the particle size of the powder was analyzed by Scanning Electron Microscope (SEM) (JEOL, JSM 5410, Japan.). Finally, the powder analyzed for its individual elemental composition percentage by weight using Energy Dispersive $\mathrm{X}$-ray Spectroscopy (EDX) analysis

\section{Preparation of remineralizing agents}

The remineralizing CESP solution and slurry were prepared at Physics Department, Faculty of Science, Tanta University. For CESP solution a one gram of the prepared chicken egg shell powder was dissolved in $33.3 \mathrm{ml}$ of sterile deionized water until reaching $3 \%$ concentration. While the CESP slurry a one gram of the prepared chicken egg shell powder was mixed with $2 \mathrm{ml}$ of artificial saliva ${ }^{[12]}$.

\section{Application of the remineralizing agents}

For Group I: The demineralized specimens were immersed individually in separate test tubes twice daily (morning and evening) in CESP solution for 12 minutes at $37^{\circ} \mathrm{C}$. Then removed and rinsed 
with deionized water for 5 seconds to eliminate the excess material and was kept in artificial saliva at $37^{\circ} \mathrm{C}$ for the rest of the day. This cycle was repeated for seven consecutive days and the CESP solution was refreshed daily ${ }^{[16]}$.

For Group II: The demineralized specimens were rubbed by finger with freshly mixed CESP slurry for 2 minutes twice daily (morning and evening), Then removed and rinsed with deionized water for 5 seconds to eliminate the excess material and was kept in artificial saliva at $37^{\circ} \mathrm{C}$ for the rest of the day. This cycle was repeated for seven consecutive days.

Elemental analysis (EDX) and surface Microhardness were conducted again after the remineralization procedure.

\section{PH cycling after treatment}

Following application of the remineralizing agents, The $\mathrm{pH}$-cycling models were used to simulate daily acidic challenge in the oral environment, the teeth were immersed in the demineralizing solution for $3 \mathrm{~h}$ and after rinsing with deionized water for 5 seconds. They were immersed in the prepared remineralizing agent $(1.5 \mathrm{mMol}$ Calcium Chloride- 0.9 mMol Sodium Phosphate- $150 \mathrm{mMol}$ Potassium Chloride) for the rest of $24 \mathrm{~h}$. This cycle was repeated for five consecutive days; the demineralizing and remineralizing solutions were refreshed daily. A total of ten cycles were conducted. After each immersion the samples were washed by deionized water and kept in artificial saliva for thirty minutes ${ }^{[25]}$

Finally, Elemental analysis (EDX) and surface Microhardness were performed after $\mathrm{pH}$ cycling step.

\section{Statistical Analysis}

Statistical Analysis was performed using IBM ${ }^{\circledR}$ SPSS ${ }^{\circledR}$ program version 22.0.Q. Numerical Data were explored for normality checking the distribution of data and using tests of normality (Kolmogrov-Smirnov and Shapiro-WilK tests). All data showed normal (parametric) distribution. Data were presented as mean and standard deviation (SD) values. One-way ANOVA was used to compare between the groups. Tukkey's post hoc test was used for pair-wise comparisons. All analysis was performed with a significance level set at 5\% $(\mathrm{P} \leq 0.05)$.

\section{RESULTS}

\section{Characterization of the prepared CESP}

$X$-ray diffraction $(X R D)$ analysis: $\mathrm{XRD}$ patterns of natural eggshells before and after calcinations are shown in Fig. 1. The main peak of raw eggshells before calcination (Fig. 1. a ) appears at $2 \theta=29.399$ indicating calcium carbonate $\left(\mathrm{CaCO}_{3}\right)$, calcite or a rhombohedral phase formation (JCPDS No. 01086-0174). Other small peaks appear at $2 \theta=23.31$, $36.23,39.70,43.46,47.81,48.78$ and 57.72 .

The main XRD peaks of the calcinied eggshells (Fig. 1.b) can be seen at $2 \theta$ equal to $18.4,23.09$, 28.78, 29.49, 34.21, 47.65, 50.94, 54.54 and 63.15. The eggshell peaks calcined at $900{ }^{\circ} \mathrm{C}$ for $1 \mathrm{~h}$ correspond to the calcium oxide $(\mathrm{CaO})$ or the lime of the face-centered cubic form, with a small amount

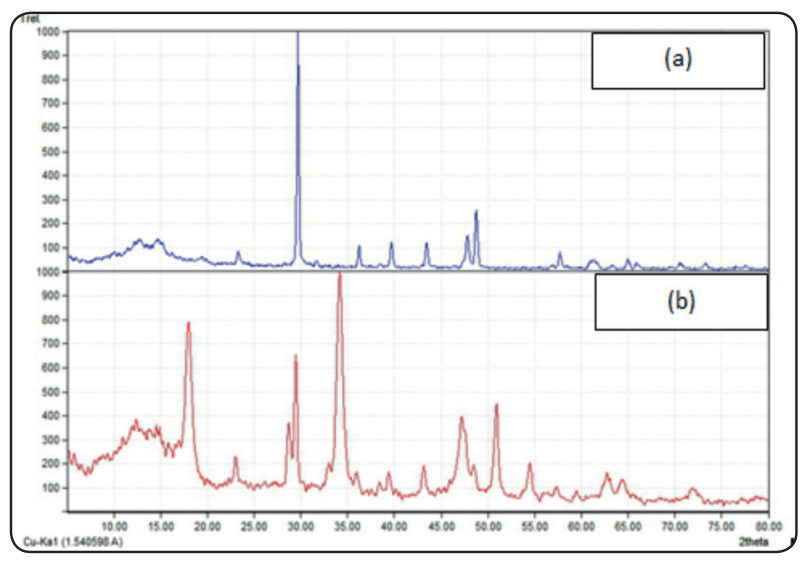

Fig. (1) Qualitative XRD phase study of both uncalcinied (a) and calcinied (b) powders of the eggshell. 
of calcium hydroxide $\left(\mathrm{Ca}(\mathrm{OH})_{2}\right)$ or portlandite) of the hexagonal form as a result of to the moisture absorption. The $\mathrm{CaO}$ crystallite size was calculated using the Scherrer'sequation. The calcinied eggshell generated nanocrystalline $\mathrm{CaO}$ with a crystallite size of $25 \mathrm{~nm}$.

Scanning electron microscope images (SEM): the micrographs of uncalcinied and calcinied eggshell powder are shown in Fig. 2. The morphology of uncalcinied eggshell powder (a) turned out to be irregular in shape. Occurrence of particles of various sizes were also noticeable in this case with powder particle size range from $25 \mu \mathrm{m}$. to $200 \mu \mathrm{m}$. The morphology of calcinied eggshell powder nearly round shape particles of calcinied eggshell powder were found for all the samples, with agglomeration of particles giving the shape of cloud. The powder particle size range from $75 \mathrm{~nm}$. to $210 \mathrm{~nm}$.

\section{Energy Dispersive X-ray spectroscopy (EDX) analysis (Fig.2)}

EDX of the prepared CESP powder: The result represents the amount of $\mathrm{Ca}$ and $\mathrm{P}$ present in the samples. The elemental composition obtained was $\mathrm{Ca}: 96 \mathrm{wt} \%, \mathrm{P}: 1.83 \mathrm{wt} \%$. The impurity elements such as $\mathrm{Zn}, \mathrm{Cu}, \mathrm{Mg}$ and $\mathrm{C}$ were normally found in eggshells along with $\mathrm{Ca}$ and $\mathrm{P}$.

\section{EDX spectra of enamel surface of specimens:} The changes in the concentration of the total mineral components of human enamel in the different groups are summarized in table (1) and presented in figure (3). One way ANOVA results showed that the (+ve) control group had the statistically significantly highest mean $\mathrm{Ca} / \mathrm{P}$ wt\% $(2.09 \pm 0.03)$. While the demineralized specimens (-ve control group) had the statistically significantly lowest mean $\mathrm{Ca} / \mathrm{P}$ wt\% $(1.72 \pm 0.08)$. Irrespective to the treatment group there was no statistically significant difference in the mean $\mathrm{Ca} / \mathrm{P}$ wt\% between GpI and Gp II; both showed statistically significantly higher mean $\mathrm{Ca} / \mathrm{P}$ wt $\%$ than that demineralized group (-ve control group) and statistically insignificantly lower mean $\mathrm{Ca} / \mathrm{P} \mathrm{wt} \%$ than that of sound enamel(+ve control group). Following acidic challenge through $\mathrm{pH}$ cycling, there is no significant difference between the mean $\mathrm{Ca} / \mathrm{P}$ wt $\%$ recorded in both groups and that of (+ve ) control group.

\section{Microhardness}

One way ANOVA results showed statistically significantly difference between the groups at $\mathrm{P} \leq 0.001$. Results also revealed that the (+ve) control group had the statistically significantly highest mean hardness $(313.3 \pm 8.96 \mathrm{VHN})$, while the demineralized group (-ve control group) had the statistically significantly lowest mean hardness

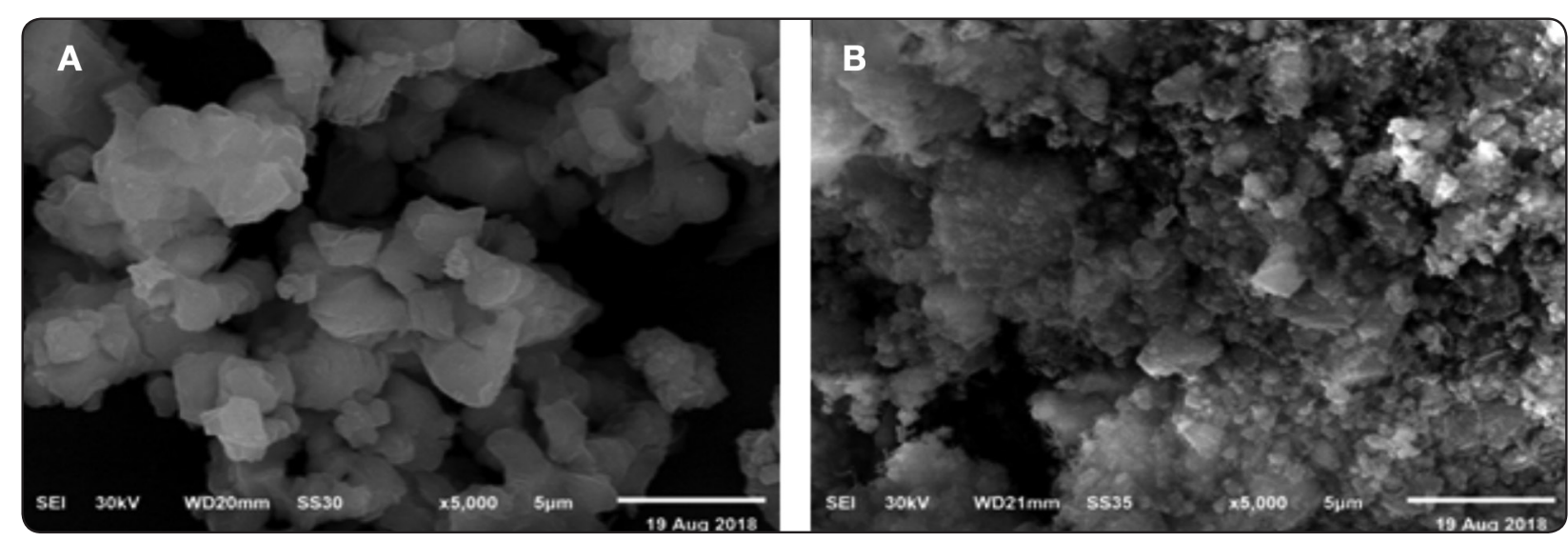

Fig. (2) SEM micrographs of uncalcined (a) and calcined (b) eggshell powder 
(195.5 $\pm 4.65 \mathrm{VHN})$. Moreover, there was no statistical significant difference between the group I and II (274.07 \pm 6.31 and $280.53 \pm 8.05$ respectively), both showed a statistically significantly higher mean hardness than that demineralized group (-ve control group) and lower hardness than (+ve) control group. The mean VHN after pH-cycling in the treated groups varied significantly from the control group $(\mathrm{p}<0.000)$. There were no significantly differences in mean VHN after $\mathrm{pH}$-cycling among the treatment groups and that of (+ve ) control group as summarized in table (2).

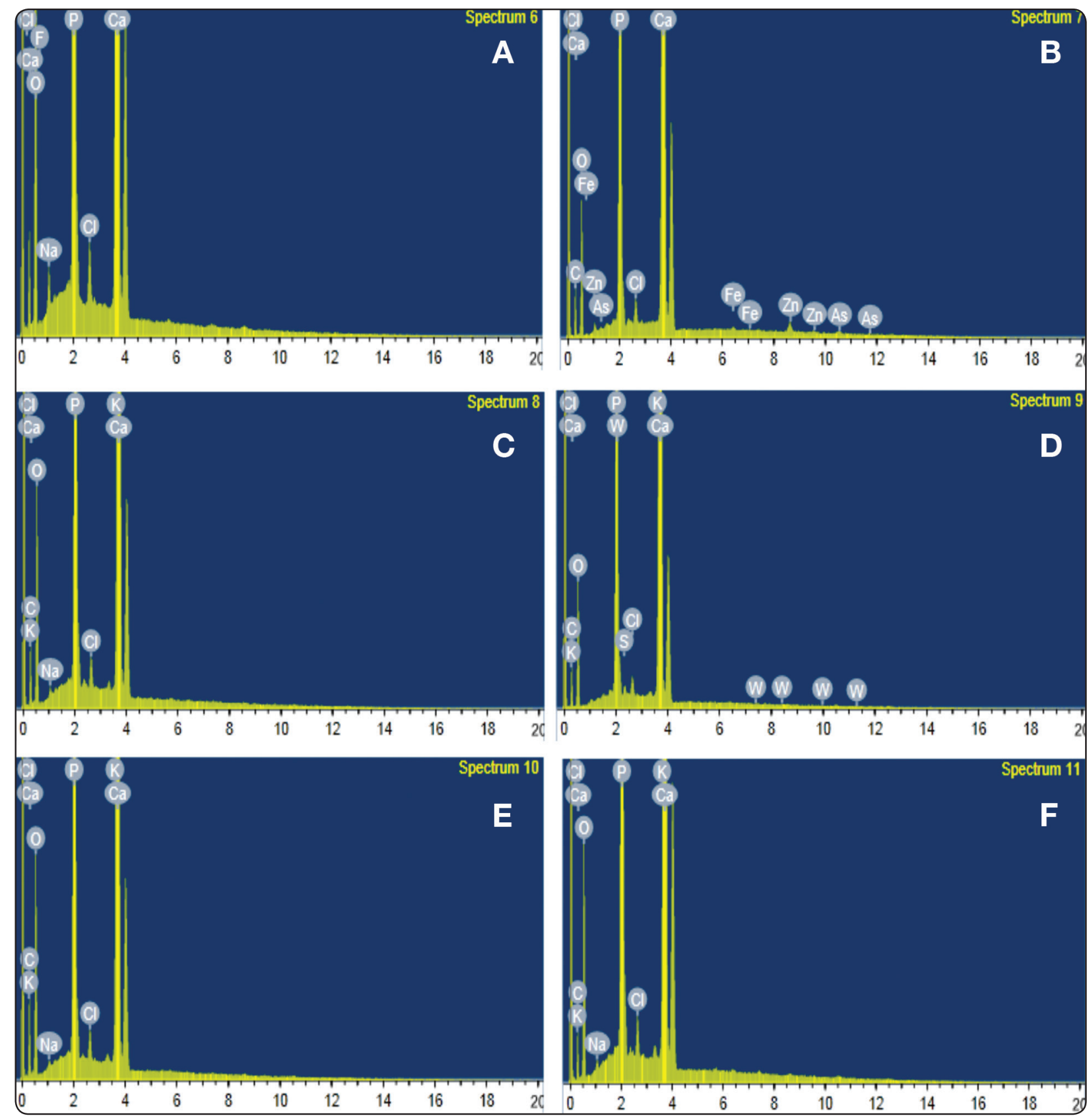

Fig. (3) Representative figures for the elemental analysis by EDX spectra of enamel surface of specimens of a) sound enamel(+ve control), b) demineralized enamel (-ve control), c) enamel treated with CESP solution (group I ),d) enamel treated with CESP slurry (group II ), e) enamel treated with CESP solution followed by $\mathrm{pH}$ cycling models , f) enamel treated with CESP slurry followed by $\mathrm{pH}$ cycling models . 
TABLE (1): The mean, standard deviation (SD) values of $\mathrm{Ca} / \mathrm{P}$ wt $\%$ of the different groups

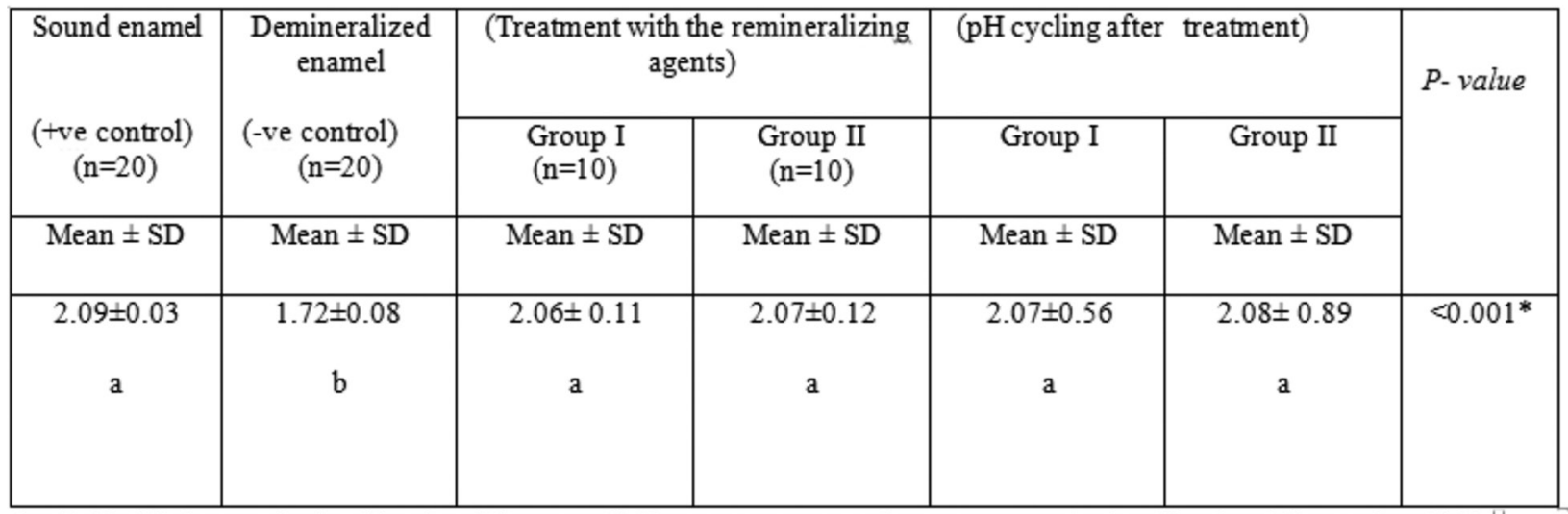

$*: P \leq 0.05$ is statistically significant, different superscripts are statistically significantly different

Table (2): The mean, standard deviation (SD) values of microhardness of the different groups

\begin{tabular}{|c|c|c|c|c|c|c|}
\hline Sound enamel & $\begin{array}{c}\text { Demineralized } \\
\text { enamel } \\
\begin{array}{c}\text { (+ve control) } \\
(\mathrm{n}=20)\end{array}\end{array}$ & $\begin{array}{c}\text { (-ve control }) \\
(\mathrm{n}=20)\end{array}$ & $\begin{array}{c}\text { Group I } \\
(\mathrm{n}=10)\end{array}$ & $\begin{array}{c}\text { Group II } \\
(\mathrm{n}=10)\end{array}$ & Group I & Group II \\
\cline { 3 - 7 } & Mean \pm SD & Mean \pm SD & Mean \pm SD & Mean \pm SD & Mean \pm SD \\
\hline Mean \pm SD & $195.5 \pm 4.65$ & $274.07 \pm 6.31$ & $280.53 \pm 8.05$ & $263 \pm 6.63$ & $265.43 \pm 10.5$ & $<0.001^{*}$ \\
\hline $313.3 \pm 8.96$ & $\mathrm{c}$ & $\mathrm{b}$ & $\mathrm{b}$ & $\mathrm{b}$ & $\mathrm{b}$ & \\
$\mathrm{a}$ & & & & & & \\
\hline
\end{tabular}

$*: P \leq 0.05$ is statistically significant, different superscripts are statistically significantly different

\section{DISCUSSION}

Nowadays, the objective of current dentistry is to manage incipient caries lesions non-invasively to prevent disease progression and enhance aesthetics, strength, and function of teeth. The development of a remineralization protocol that inhibits demineralization and encourages remineralization remains a challenge in this field. So, this study sought to assess and compare the enamel remineralization potential of CESP solution or slurry on artificially initiated demineralized enamel in human permanent teeth.

The most significant feature of initial enamel lesions is the presence of relatively intact surface layer overlying subsurface demineralization. How- ever, they have a decreased mineral content at the surface layer when compared to sound enamel; thus showing a lesser hardness value than sound enamel tissue. ${ }^{[12]}$

Demineralization continues as long as sufficient acid is available. As more enamel dissolves, concentration of the $\mathrm{Ca}$ ion and $\mathrm{PO}_{4}$ ion increase and diffuse outwards giving an environment that enables the repair of the damaged crystallites underneath the surface of enamel and facilitates remineralization. This leads to the formation of an actually intact enamel surface layer about 20-40 microns where the mineral content is greater than the body of the lesion. ${ }^{[16,26]}$ 
To mimic subsurface carious lesions in vitro while maintaining the superficial layer, weak organic acids such as lactic or acetic acid are used in the composition of the demineralizing agent ${ }^{[27,28]}$. Furthermore, the presence of calcium and phosphate, in the solution, helps preserve the superficial layer while enhancing mineral loss from the subsurface layer. For this reason, a demineralizing agent containing calcium, phosphate, acetic acid (weak acid) was used ${ }^{[29]}$.

In the present study, the specimens were kept in the demineralization solution for 96 hours at $37^{\circ} \mathrm{C}$ to make a subsurface demineralization of approximately 150 microns width with an intact surface mimicking an early enamel lesion. While, the period for demineralization in the $\mathrm{pH}$ cycling phase was three hours, which simulate the duration of demineralization that occurs in the oral cavity ${ }^{[16]}$.

Over many years the cornerstone of the non-invasive management of incipient carious lesions was fluoride, but its ability to promote net remineralization is limited mainly because its action is confined by the availability of Calcium and Phosphate ions ${ }^{[30]}$. This lead to the search for new remineralization technologies utilizing different agents which have proven success in this field, as casein phosphorpeptide amorphous calcium phosphate (CCP-ACP), dicalcium phosphate (DCP), tricalcium phosphate (TCP), bioactive glass and nanohydroxyapatite ${ }^{[31]}$.

In recent years, chicken eggshell has attaining importance in numerous fields ${ }^{[32,33]}$. Mony, et al., $2015^{[16]}$ returned the important role of CESP in enamel remineralization when applied topically to the high concentration of bioavailable $\mathrm{Ca}$.

The calcination process of CESP was performed to get pure powder free of pathogens and to increase the alkalinity of powder ${ }^{[34]}$. This alkalinity is favorable for the increased ionic activity of anions such as hydroxyl ions and phosphate ions. Thus more ions are existing for enamel remineralization. If the $\mathrm{pH}$ of remineralizing solution is low there will be more concentration of $\mathrm{H}^{+}$ions which combines with the available anions and thus less ions will be available for remineralization ${ }^{[21,35]}$.

The X-ray diffraction (XRD) showed that phase transformation from calcium carbonate to calcium oxide starts to occur at $900{ }^{\circ} \mathrm{C}$ after $1 \mathrm{~h}$ calcination. Furthermore, a small amount of calcium hydroxide $\left[\mathrm{Ca}(\mathrm{OH})_{2}\right]$ appeared due to a reactive moisture adsorption. The phase transformation thus depends on a calcination temperature and time ${ }^{[36]}$.

Scanning electron microscope images (SEM) of CESP revealed that the egg shell nanoparticles were smooth, spherical shaped with size ranging from $100 \mathrm{~nm}$ to $200 \mathrm{~nm}$. The nanoparticles were clumped together to form clusters, giving a cloudy appearance which attributed to a greater surface tension for the high temperature of decarbonated samples .Since absorption of moisture seemed to be augmented to a great extent for the high temperature calcined products, the formation of $\mathrm{Ca}(\mathrm{OH})_{2}$ phase with hexagonal structure could not be avoided. As a matter of fact, particle agglomeration resulted ${ }^{[17]}$.

Huang et al. $2009^{[37]}$ demonstrated that calcium carbonate nanoparticles were sphere-shaped and conglomerated. In their study, the surface of the nanoparticles was smooth with diameters ranging from $100 \mathrm{~nm}$ to $200 \mathrm{~nm}$, which is in agreement with the finding of the present study.

Various methods have been used to study remineralization of carious lesions, such as microradiography, polarized light microscopy, microhardness, mineral analysis of calcium phosphate phases, transmission and scanning electron microscopy ${ }^{[38]}$. One of the recent technique that are used to quantitatively measures the small changes in the mineral content is Energy Dispersive X-ray spectroscopy $(\mathrm{EDX})^{[39]}$. EDX analysis of CESP has been conducted in order to evaluate the elemental composition of the material. The results of atomic analysis by EDX showed that the elemental composition obtained were $\mathrm{Ca}: 96 \mathrm{wt} \%, \mathrm{P}: 1.83 \mathrm{wt} \%$ which agreed with the findings done by Mony, et al., $2015^{[16]}$. 
Following the application of remineralizing agents (CESP solution or slurry) on enamel carieslike lesions, it appears that mineral ions diffused into the superficial layer obstruct the surface porosities. This explains the significant difference in mean $\mathrm{Ca} / \mathrm{P} \mathrm{wt} \%$ and hardness of remineralized and demineralized enamel samples in our study ${ }^{[19]}$.

The $\mathrm{pH}$ cycling protocol followed in the present study is of particular interest because it simulates in vivo high caries risk condition and simultaneously measures the net result of the inhibition of demineralization and the enhancement of remineralization ${ }^{[39]}$. In this model, the dynamic cycles of de- and re-mineralization are simulated by sequentially immersing enamel specimens in acidic (demineralizing) and supersaturated (remineralizing) buffer solutions. These de- and remineralization solutions approximate the mineral ion composition and supersaturation of saliva as originally reported by ten Cate and Duijsters ${ }^{[40]}$.

Moreover, the non-significant differences in the mean $\mathrm{Ca} / \mathrm{P} \mathrm{wt} \%$ of reminerlized enamel samples after $\mathrm{pH}$ cycle and sound enamel indicating that the reminerlizing effect of CESP solution and slurry can resists the cariogenic attack in oral cavity. The results of present study are consistent with previous studies that showed the efficacy of CESP in remineralization of the enamel surface ${ }^{[9-12]}$.

Considering the importance of the surface layer in caries progression, the assessment of changes in this region is important. Surface micro hardness $(\mathrm{SMH})$ provides a relatively simple, nondestructive and rapid technique in demineralization and remineralization studies ${ }^{[41,42]}$.

The mean values of VHN obtained during the initial base line micro hardness measurements in the present study satisfied the VHN range of normal enamel tissue ${ }^{[34]}$, which indicates the random distribution of the samples in the two groups. While, at the end of 96 hours of demineralization, The surface micro hardness values for each group of the enamel specimens were decreased which is in accordance with the study conducted by Maupome et al.,1999 ${ }^{[43]}$.

Furthermore, changes in $\mathrm{Ca} / \mathrm{P}$ wt $\%$ and microhardness during the experiment were significant in the two groups. microhardness significantly decreased following exposure to demineralizing solution while it significantly increased following application of the remineralizing agent; this indicates the efficacy of both remineralization protocol (immersion in CESP solution or rubbing with CESP slurry) for the remineralization of incipient enamel caries-like lesions .

Following the application of remineralizing agents on enamel caries-like lesions, it appears that mineral ions diffused into the superficial layer obstruct the surface porosities; further diffusion of minerals is limited after reaching a plateau ${ }^{[18]}$. This explains the lack of a significant difference in remineralization of lesions following the use of CESP solution and slurry solutions in our study which is confirmed by EDX and SMH analysis.

Our study results are in accordance with those of previous studies done to assess the protective effects of fluoride containing products on initial enamel caries. According to which fluoride can protect the enamel against acidic attack but cannot completely prevent the process of demineralization ${ }^{[44-47]}$.

Finally it worth mentioned that remineralization of initial lesion should be targeted to enhance shifting from destructive drill and fill policy to a more consevative one. Therefore, the rich bioavailability of calcium along with the high concentration of phosphates present in CESP coupled with its increased $\mathrm{pH}$ may be responsible for remineralization ${ }^{[36]}$

The null hypothesis was accepted as the remineralization potential of CESP solution and slurry has the similar effect on demineralized enamel. However additional studies should be conducted to know what are the optimal concentration, form and application time of CESP to produce efficient remineralization 


\section{CONCLUSION}

Within the limitation of this in vitro study, the following conclusions were derived:

1- CESP has a promising future in treating initial enamel surfaces lesion due to its natural source and easy bioavailability and can be considered as an optimal alternative to the commercial ones.

2- Remineralization using CESP solution has a similar efficacy to that of topical application of CESP slurry using finger rubbing.

\section{RECOMMENDATIONS}

Further clinical studies are required to improve the remineralization ability of CESP to be comparable to the various commercially available remineralizing agents.

\section{REFERENCES}

1. Free RD, DeRocher K, Stock S. R., Keane D., ScottAnne K, Bowenc W. H and Joester D. Characterization of enamel caries lesions in rat molars using synchrotron $\mathrm{X}$ ray microtomography. J. Synchrotron Rad, 2017; 24:1 -9

2. Lata S, Varghese NO, VarugheseJ M.. Remineralization potential of fluoride and amorphous calcium phosphate-casein phospho peptide on enamel lesions: An in vitro comparative evaluation. J Conserv Dent, 2010; 13(1):42-46.

3. Silverstone LM, Hicks MJ, Featerstone MJ. Dynamic factors affecting lesion initiation and progression in human dental enamel, 2 Surface morphology of sound enamel and caries like lesions of enamel. Quintessence Int, 1988;19: 773-85

4. Christos Vougioklakisg. Effect of a commercial paste based on CPP-ACP complex on the demineralization of sound human dentine and on remineralization potential of artificial caries-like lesions. Caries Res, 2007;35: 695-8.

5. Sato Y, Sato T, Niwa M, Aoki H. precipitation of octa calcium phosphates on artificial enamel in artificial saliva. J Mater Sci Mater Med, 2006; 17:1173-7.

6. Cardoso CA, Cassiano LP, Costa EN, Souza-E-Silva CM, Magalhães AC, Grizzo LT, et al. Effect of xylitol varnishes on remineralization of artificial enamel caries lesions in situ. J Dent, 2016; 50:74-8.
7. Fernández-Ferrer L, Vicente-Ruíz M, García-Sanz V, Montiel J M , Paredes-Gallardo V, Almerich-Silla J M, Bellot-Arcís C,. Enamel remineralization therapies for treating postorthodontic white-spot lesions, 2018; 149(9): 778-786.

8. BejoGupta N, Mohan Marya C, Nagpal R, Singh Oberoi S, Dhingra C. Mohan G. AReview of Casein PhosphopeptideAmorphous Calcium Phosphate (CPP-ACP) and Enamel Remineralization. Compend Contin Educ Dent, 2016; 37(1):36-9; quiz 40 .

9. Dave J., Panda A., Virda M., Alwani A, Jani J. and Venkataraghavan K. Effect of Fluoridated versus Non Fluoridated Homeopathic Dentifrice on Enamel Micro Hardness: an In vitro Study. Indian J Natural Sci, 2017; 7 (41) :12074-12079.

10. Vestergaard P, Jorgensen NR, Schwarz P, Mosekilde L. Effects of treatment with fluoride on bone mineral density and fracture risk - A meta-analysis. Osteoporos Int, 2008;19: 257-68.

11. Kattimani VS, Chakravarthi PS, Kanumuru NR, Subbarao VV, Sidharthan A, Kumar TS, et al., . Eggshell derived hydroxyapatite as bone graft substitute in the healing of maxillary cystic bone defects: A preliminary report. J Int Oral Health, 2014; 6: 15-20

12. Haghgoo R, Mehran M, Ahmadvand M, Ahmadvand M.J. Remineralization Effect of Eggshell versus Nanohydroxyapatite on Caries-like Lesions in Permanent Teeth (In Vitro). J Int Oral Health, 2016; 8(4):435-439 .

13. Stadelman WJ. Eggs and egg products. In: Francis FJ, editor. Encyclo-Pedia of Food Science and Technology. 2nd ed. NewYork: John,Wiley and Sons; 2000: p. 593-9.

14. Vestergaard P, Jorgensen NR, Schwarz P, Mosekilde L. Effects of treatment with fluoride on bone mineral density and fracture risk - A meta-analysis. Osteoporos Int, 2008;19:257-68.

15. Meunier PJ, Roux C, Seeman E, Ortolani S, Badurski JE, Spector TD, et al. The effects of strontium ranelate on the risk of vertebral fracture in women with postmenopausal osteoporosis. N Engl J Med, 2004;350:459-68.

16. Mony B, Ebenezar R, Chani MF, Narayanan A, Anand S, Mohan A.G. Effect of Chicken Egg Shell Powder Solution on Early Enamel Carious Lesions: An Invitro Preliminary Study. J Clinic and Diagn Res, 2015; 9(3): ZC30-ZC32. 
17. Zaman T, Mostari MS, Al Mahmood M A, Rahman MS. Evolution and characterization of eggshell as apotential candidate of raw material. Cerâmica, 2018; 64 :236-241

18. Buasri, Achanai, Chaiyut, Nattawut, Loryuenyong, Vorrada, Wongweang, Chaiwat, Khamsrisuk, Saranpong,. Application of eggshell wastes as a heterogeneous catalyst for biodiesel production. Sustain. Energy, 2013;1: 7-13.

19. Ismail AI, Brodeur J-M, Gagnon P, Payette M, Picard D, Hamalian T, et al. Prevalence of non-cavitated and cavitated carious lesions in a random sample of 7-9-yearold school children in Montreal, Quebec. Community Dent Oral Epidemiol. 1992; 20: 250-5.

20. Nasution A.I., Gani B. A. Comparative scanning electron microscopy/energy-dispersive xray study of nano-hydroxyapatite toothpaste in correlation of remineralization. Int J Contemp Dent and Med Reviews, 2017; Article ID 011117: 1-6.

21. Huang SB, Gao SS, Yu HY.. Effect of nano-hydroxyapatite concentration on remineralization of initial enamel lesion in vitro. Biomed Mater, 2009;4: 034104.

22. Vyavhare S, Sharma DS, Kulkarni VK. Effect of three different pastes on remineralization of initial enamel lesion: an in vitro study. J Clin Pediatr Dent, 2015; 39(2):149-60.

23. Feroz S., Moeen F. Protective effect of two different remineralizing agents on artificially induced dental erosion in primary and permanent teeth: an in-vitro analysis. Pakistan Oral \& Dent J, 2017; 37(4): 657-666.

24. Methods of producing egg shell powder: Patents: US 20060062857 A1.

25. Yassen AA and Safy RK. Grape seed extract and dentin remineralization. Egy Dent J, 2018; 64: 897-904.

26. Haghgou H R, Haghgoo R, Roholahi M R, Ghorbani Z. Effect of Casein Phosphopeptide-Amorphous Calcium Phosphate and Three Calcium Phosphate on Enamel Microhardness. J Contemp Dent Pract, 2017;18(7):583-586.

27. Featherstone JD. Modeling the caries inhibitory effects of dental materials. Dent Mater, 1996;12:194-7.

28. Magalhaes AC, Moron BM, Comar LP, Wiegand A, Buchalla W, Buzalaf MA. Comparison of cross sectional hardness \& transverse microradiography of artificial carious enamel lesions induced by different demineralizing solutions and gels. Caries Res, 2009; 43:474-83.

29. de Groot JF, Borggreven JM, Driessens FC. Some aspects of artificial caries lesion formation of human dental enamel in vitro. J Biol Buccale,1986;14:125-31.
30. Lippert F, Hara AT, Martinez-Mier EA, Zero DT. Laboratory investigations into the potential anticaries efficacy of fluoride varnishes. Pediatr Dent. 2014; 36: 291-5.

31. Llena C, Leyda AM, Forner L. CPP-ACP and CPP-ACFP versus fluoride varnish in remineralisation of early caries lesions. A prospective study. Eur J Paediatr Dent 2015;16: 181-6.

32. Rovensky J SM, Masaryk P, Svik K, Istok R. . Eggshell calcium in the prevention and treatment of osteoprosis. Int J Clin Pharmacol Res, 2003; 23(2-3). 83-92.

33. Schaafsma A DJ, Muskiet FA, Hofstede GJ, Pakan I, van der Veer E. Positive effects of a chicken eggshell powder -enriched vitamin-mineral supplement on femoral neck bone mineral densityin healthy late post-menopausal Dutch women. Br J Nutr, 2002; 87(3): 267-75.

34. Shen P MD, Cochrane NJ, Walker GD, Yuan Y, Reynolds $\mathrm{C}$, et al.,. Effect of added calcium phosphate on enamel remineralization by fluoride in a randomized controlled in situ trial. J Dent, 2011; 39: 518-25.

35. Hicks J G-GF, Flaitz C. Biological factors in dental caries enamel structure and the caries process in the dynamic process of demineralization and remineralization (part 2). J Clin Pediatr Dent, 2004; 28: 119-24.

36. Tangboriboon N., Kunanuruksapong R., Sirivat A. Preparation and properties of calcium oxide from eggshells via calcination. Mater Sci-Poland, 2012; 30(4): 313-322

37. Huang, S., Ching, J., Hsu, C.W. \& Chang, W.H. Effects of nano calcium carbonate and nano calcium citrate on toxicity in ICR mice and on bone mineral density in an ovariectomized mice model. Nanotechnology, 2009; 20:201-207

38. Buzalaf MA, Hannas AR, Magalhães AC, Rios D, Honório HM, Delbem AC. pH-cycling models for in vitro evaluation of the ef $\neg$ ficacy of fluoridated dentifrices for caries control: strengths and limitations. J Appl Oral Sci, 2010; 18: 316-34.

39. Salman NR,. El-Tekeya MM, Bakry N, Soliman S. Remineralization effect of fluoride varnish containing casein phosphopeptide amorphous calcium phosphate on caries-like lesions in primary teeth (In Vitro study). Alex. Dent J, 2019;44 :13-16

40. ten Cate JM, Duijsters PP. Alternating deminer $\neg$ alization and remineralization of artificial enamel lesions. Caries Res, 1982; 16: 201-10. 
41. Ren Y ZQ, Malmstrom H, Barnes V,Xu T. Assessing fluoride treatment and resistance of dental enamel to soft drink erosion in vitro: Applcations of focus variation 3D scanning microscopy and stylus profilometry. J Dent, 2009; 37:167-76.

42. Ryge G, Foley DE, Faorhurst CW. Micro-indentation hardness. J Dent Res,1961;40:1116-26.

43. Maupomé G, Aguilar-Avila M, Medrano-Ugalde H, Borges-Yáñez A). In vitro quantitative micro hardness assessment of enamel with early salivary pellicles after exposure to an eroding cola drink. Caries Res,1999; 33: $140-7$

44. Queiroz CS, Hara AT, Paes Leme AF, Cury JA. pH-cycling models to evaluate the effect of low fluoride dentifrice on enamel de- and remineralization.Braz Dent J, 2008; 19:21-7.

45. Somasundaram P, Vimala N, Mandke LG. Protective potential of casein phosphopeptide amorphous calcium phosphate containing paste on enamel surfaces. J Conserv Dent, 2013;16:152-6.

46. Rirattanapong $\mathrm{P}$, Vongsavan $\mathrm{K}$, Saengsirinavin $\mathrm{C}$, Pornmahala T. Effect of fluoride varnishes containing tricalcium phosphate sources on remineralization of initial primary enamel lesions. Southeast Asian J Trop Med Public Health, 2014;45:499-504.

47. Mohd Said SN, Ekambaram M, Yiu CK. Effect of different fluoride varnishes on remineralization of artificial enamel carious lesions. Int J Paediatr Dent, 2017; 27:163-73. 